\title{
BBEP
}

\section{A neutralização das discriminações por meio da educação da criança}

Klondy Lúcia de Oliveira Agra

\section{Resumo}

Discorre brevemente, a partir de pesquisa bibliográfica e etnográfica, sobre as ações afirmativas implantadas no Brasil a partir dos anos 90 e discute os diversos olhares que as perpassam, com o objetivo de apontar, com auxílio das teorias culturais, caminhos para a promoção da inclusão e da justiça que ultrapassem a teoria e conduzam à prática, mediante a educação da criança desde a primeira infância.

Palavras-chave: educação; inclusão; ações afirmativas.

\section{Abstract}

The discrimination neutralization through children education

The present article argues from bibliographic and ethnographic research, shortly, about the affirmative actions implanted in Brazil from years on 90 and argue the several looks that pass by them, with the goal of pointing, with help from cultural theories, ways for the promotion of the inclusion and justice that will go besides the theory and lead the practice through the child's education since the first childhood.

Keywords: education; inclusion; affirmative actions. 
Para ser universal ou inclusivo, isto é, para não excluir, só falta exercitar a empatia, que é a capacidade de se pôr no lugar do outro, constantemente. ${ }^{1}$

Humberto Eco

\section{Introdução}

A cultura do povo brasileiro, por trazer arraigada em si as características de um país colonizado, apresenta vários vieses. São esses vieses culturais que dão origem aos preconceitos de toda ordem, tornando mais difícil a aceitação de medidas que apontem a igualdade social e cultural. Exatamente por isso, a sociedade brasileira, herdeira desse processo de colonização, é marcada por assustadores níveis de exclusão.

Neste artigo, a partir de estudo bibliográfico e de resultado de pesquisas etnográficas, discorrerei brevemente sobre as ações afirmativas implantadas no Brasil a partir dos anos 90, observando os diversos olhares que as perpassam, com o objetivo de apontar, com auxílio das teorias culturais, caminhos para a promoção da inclusão e da justiça que ultrapassem a teoria e conduzam à prática por meio da educação da criança desde a primeira infância. Tal estudo é feito com a crença de que é a educação o alicerce para uma sociedade mais empática, com a quebra de preconceitos e a inclusão social e cultural.

Temos observado que a discussão e a aplicação das políticas de ações afirmativas no Brasil vêm se mostrando como um desafio. Esse desafio pode ser traduzido como uma mescla de novas perspectivas e métodos com as mais diversas críticas aos resultados obtidos.

Ações afirmativas, neste artigo, são compreendidas como formas de políticas públicas ou privadas que objetivam ir além das ações do Estado na promoção do bem-estar e da cidadania para garantir igualdade de oportunidades com intenção de ampliar as ações de inclusão social. Em Joaquim Gomes (2001, p. 6-7) encontramos o seguinte conceito:

Consistem em políticas públicas (e também privadas) voltadas à concretização do princípio constitucional da igualdade material e a neutralização dos efeitos da discriminação racial, de gênero, de idade, de origem nacional, de compleição física e situação socioeconômica (adição nossa). Impostas ou sugeridas pelo Estado, por seus entes vinculados e até mesmo por entidades puramente privadas, elas visam a combater não somente a discriminação de fundo cultural, estrutural, enraizada na sociedade. De cunho pedagógico e não raramente impregnadas de um caráter de exemplaridade, têm como meta, também, o engendramento de transformações culturais e sociais relevantes, inculcando nos atores sociais a utilidade e a necessidade de observância dos princípios do pluralismo e da diversidade nas mais diversas esferas do convívio humano.

Com o objetivo de discutir essas ações afirmativas e os vários pontos de vista que as permeiam, acredito ser necessário clarear e compreender a formação da sociedade brasileira e os vários conceitos inclusos nesse 
tema. Conceitos muito ecoados no Brasil, muitas vezes carregados de demagogia e preconceitos.

O racismo, a raça e a brancura são conceitos presentes nos diversos olhares sobre as ações afirmativas brasileiras e caminham lado a lado a elas.

Vejo o racismo nesta discussão, de acordo com a definição encontrada em Enid Lee (1993, p. 103): racismo é "qualquer ato ou idéia que limita, nega ou concede oportunidades, serviços, recursos, direitos ou respeito para uma pessoa com base na cor da pele"2 [Minha tradução].

Quanto à raça, recorro a escritores e teoristas que a definem de modos variados. Tais definições englobam o biológico e o social. Após várias leituras, permaneço com a definição de Lee (1985, p. 12): raça é: "uma categoria social usada para classificar a espécie humana de acordo com seus ancestrais ou descendentes comuns ou em diferenciação por características físicas gerais como cor de pele e olhos, tipo de cabelo, estatura e características faciais". ${ }^{3}$ [Minha tradução]

Na observação das várias definições de raça, em teorias diversas, (Sleeter, 1999; McIntosh, 1999; Delgado, Stefancic, 1997) nota-se que a brancura da pele, reconhecida ou não, tem sido uma medida nessa definição. E que, por ter sido uma regra para o reconhecimento de outras raças, tal brancura faz com que raça passe a ser examinada em termos de economia, vantagem e desvantagem. Ademais, por ser a definição de raça mediada pela cor, reconhece-se, também, o motivo de o racismo dar a ideia de concessão de oportunidades e recursos para alguns e a negação para outros.

Para dar continuidade a essa discussão, torna-se necessário lembrar o fato de o Brasil ser um país de miscigenação de raças, o segundo em população negra fora da África, onde pretos e pardos representam cerca de 50\% da população. Tem, ainda, cerca de 315.000 índios (206 etnias, concentradas, em sua maioria, numa parcela da Amazônia Legal, que engloba seis Estados: Amazonas, Acre, Roraima, Rondônia, Mato Grosso e Pará), com mais de 40 povos isolados na Amazônia Ocidental, e recebeu (e recebe) pessoas vindas de países Europeus, Africanos e Asiáticos. Por isso mesmo, possui uma variedade riquíssima de culturas e raças que nem sempre são respeitadas. Isso significa que, desde sua colonização, o Brasil é diverso em etnia e em cultura, partindo daí as diversidades de pensamentos e pontos de vista, revelando a veracidade da assertiva: culturas diferentes, pontos de vista diferentes.

Com base nesses conceitos, apresento este debate que me possibilitou reflexão sobre questões como cultura brasileira, raça, racismo, brancura, formação do professor, construção de saberes e relacionamentos professor/aluno - as representações envolvidas nessa interação, sentidos e significados - e, principalmente, a importância de se educar a criança para a real aplicabilidade das ações afirmativas no Brasil, sendo essa educação fundamental para a formação de uma sociedade mais empática e, por isso, mais aberta a reconhecer e a respeitar as diferenças.

\footnotetext{
2 "Any act or idea which limits, denies or grants opportunities, services, resources, rights or respect to a person on the basis of skin colour."

3 "A social category used to classify human kind according to common ancestry or descent and reliant upon differentiation by general physical characteristics such as colour of skin and eyes, hair type, stature, and facial features."
} 


\section{Ações afirmativas do Brasil}

As políticas públicas brasileiras, historicamente, têm-se caracterizado por adotar uma perspectiva social, medidas redistributivas ou assistenciais contra a pobreza com base em concepções de igualdade, sejam elas formuladas por políticos de direita ou de esquerda (Munanga, 1996).

No entanto, com a redemocratização do País, conhecimentos e informações trocadas com mais velocidade sobre leis e direitos, a sociedade brasileira passou a exigir medidas que atendessem questões sobre raça, gênero e etnia, por meio de providências mais abrangentes.

Desse modo, com a necessidade de procurar soluções para as diferenças no Brasil, surgiram políticas afirmativas sob diferenciadas formas, como: atividades voluntárias, de caráter obrigatório, estratégias mistas, com programas governamentais ou privados, e leis e obrigações a partir de decisões jurídicas e de agências de fomento ou de regularização.

O público alvo dessas ações afirmativas abrange minorias étnicas, raciais e mulheres, contemplando o mercado de trabalho com treinamento, contratação e qualificação de funcionários; o sistema educacional, em especial o ensino superior; e a representação política.

Uma das medidas mais conhecidas e também mais polêmicas é o sistema de cotas. Um sistema que consiste em estabelecer determinado número ou percentual a ser ocupado em área específica por grupo definido.

A polêmica sobre esse sistema aparece à medida que os vieses culturais afloram expondo valores arraigados de preconceitos. Valores de uma sociedade racista onde propostas em benefício dos excluídos recebem forte oposição com o intuito de constrangê-las.

Segundo Antônio Guimarães (1999, p. 166), os argumentos contrários a ações afirmativas tomam três direções:

Primeiramente, para alguns, as ações afirmativas significam o reconhecimento de diferenças étnicas e raciais entre os brasileiros, o que contraria o credo nacional de que somos um só povo, uma só raça. Em segundo lugar, há aqueles que vêem em discriminações positivas um rechaço ao princípio universalista e individualista do mérito, princípio que deve ser a principal arma contra o particularismo e o personalismo, que ainda orientam a vida pública brasileira; finalmente, para outros, não existem possibilidades reais, práticas, para a implementação dessas políticas no Brasil.

Com a implementação do sistema de cotas por algumas universidades brasileiras, assistimos em todo o País pessoas que sempre negaram a origem africana de seus antecedentes, sem nenhum traço dessa raça, brigando judicialmente pelo acesso ao sistema. Outros, por não conseguirem vagas, recorrendo à justiça apoiados no princípio da igualdade constitucional do País.

Diferentes interpretações da Constituição e posturas distintas em termos normativos com relação às noções de igualdade e justiça são os pontos-chave dessas disputas. O princípio da igualdade perante a lei está 
presente nas constituições brasileiras desde o Império, passando por algumas transformações ao longo desses anos.

A pergunta que prevalece, num cenário marcado pela diferença de pensamentos, valores e pontos de vista no que concerne às políticas de ação afirmativa, é esta: seria possível encontrar sustentação legal para aplicação dessas ações afirmativas ou elas seriam inconstitucionais, principalmente por ferirem o princípio da igualdade garantido na Constituição de 1988?

Em parecer elaborado pela Comissão de Constituição, Justiça e Cidadania, a respeito do Projeto de Lei no 13, de 1995, apresentado pela senadora Benedita da Silva, que "dispõe sobre a instituição de cota mínima de $20 \%$ das vagas das instituições públicas de ensino superior para alunos carentes, concluiu-se pela sua inconstitucionalidade e inadequação aos preceitos constitucionais." A iniciativa do projeto de oferecer melhores condições para o acesso de alunos carentes ao ensino universitário foi considerada meritória, todavia, entendeu-se que ela feriria as normas constitucionais, como a norma presente no art. 5. De acordo com o relatório, o princípio da igualdade, como igualdade perante a lei, que significa dizer "que a lei e sua aplicação tratam a todos igualmente, sem levar em conta distinções", sempre esteve presente nas constituições do País, e a Constituição de 1988 manteria essa tradição.

Dessa forma, o parecer afirma que a Constituição atual em nada alterou o princípio da igualdade e sustenta sua inconstitucionalidade utilizando a interpretação feita por Pontes de Miranda sobre o princípio todos são iguais perante a Lei, da Constituição de 1946:

\begin{abstract}
Para aquele ilustre jurista, o princípio "todos são iguais perante a lei", dito princípio de isonomia (legislação igual), é princípio de igualdade formal: apenas diz que o concedido pela lei a A, se A satisfaz os pressupostos, deve ser concedido a B, se B também os satisfaz, para que se não trate desigualmente a B. Tão saturada desse princípio está a nossa civilização que causaria escândalo a lei que dissesse, e.g., só os brasileiros nascidos no Estado-membro A podem obter licença para venda de bebidas no Estado-membro A. Só existem exceções ao princípio da igualdade perante a lei, que é direito fundamental, [...] quando a Constituição mesma as estabelece. (Brasil, 1997, p. 3).
\end{abstract}

Além de a sociedade e os juristas terem pontos de vista contraditórios sobre o tema, revistas especializadas tomaram para si as discussões e surgiram variados artigos científicos de áreas também diversas (medicina, antropologia etc.) negando a existência de raças e opinando sobre as políticas de ações afirmativas. Com a recusa da existência de raças, desenvolve-se no Brasil um antirracismo.

De acordo com Bernardino (2004) e Guimarães (1999), evita-se falar de raça para poupar qualquer problema racial.

No Brasil "raça" não faz parte nem do vocabulário erudito nem da boa linguagem. Apenas entre pessoas "não refinadas", e nos movimentos sociais, onde militam pessoas que se sentem discriminadas por sua cor e compleição física, utiliza-se regularmente o conceito. (Guimarães, 1999, p. 19). 
Partindo desse ponto de vista antirracista, supõe-se que se não há raça, não há desigualdade racial. Com esse pensamento, falar em ações afirmativas seria incoerente e discriminatório.

No entanto, apesar das críticas contra a ação afirmativa, as experiências das últimas quatro décadas nos países que a exercitam não deixam dúvidas sobre as mudanças alcançadas. Sobre o tema, Munanga (2003, p. 118) declara:

As experiências feitas pelos países que convivem com o racismo poderiam servir de inspiração ao Brasil, respeitando as peculiaridades culturais e históricas do racismo à moda nacional. Podemos, sem copiar, aproveitar das experiências positivas e negativas vivenciadas por outros para inventar nossas próprias soluções, já que estamos sem receitas prontas para enfrentar nossas realidades raciais.

O Brasil está com décadas de atraso perante outros países na implantação de ações afirmativas, no entanto, não serão apresentados resultados se não houver uma mudança cultural. Não basta ser constitucional, a aplicabilidade de ações afirmativas necessita da conscientização de toda a sociedade; não há como falar em políticas afirmativas sem falar no respeito à diversidade. Esses resultados urgem por uma educação voltada para a empatia.

\section{Aceitação e prática das ações afirmativas}

Ações afirmativas estão nas mais variadas mídias brasileiras. Apoiado em leis, o governo tem implementado programas e divulgado campanhas sobre os temas preconceito e segregação social com o intuito de levar a população a discutir, conceituar e implementar a educação voltada para a diversidade racial e cultural, a aceitação e a prática de políticas afirmativas. No entanto, acredito que essa é uma tarefa complexa que envolve mais do que substituir atitudes negativas sobre raça e cultura por atitudes positivas, é adquirir um amplo conhecimento dessas raças e culturas.

Brasileiros brancos não foram ensinados a se verem como brancos. Tampouco nos foi ensinado a pensar a brancura como sendo importante para se respeitar a diversidade racial. De fato, somos ensinados o oposto. Nós aprendemos a ignorar a cor - é a melhor maneira de aceitar as diferenças e aceitar as diversidades. Muitos brancos repetem todos os dias: Não vejo raças, vejo pessoas. Existe só uma raça, a raça humana. Permanecendo nessa cegueira quanto à cor, brasileiros(as) acreditam que se eles(as) ignorarem a cor de pessoas que estão a sua volta, eles(as) não estão participando de nenhuma espécie de racismo.

Essa cegueira social traz grandes desafios para as políticas de ação inclusiva e sua aplicação. Isso se deve ao fato de não se trabalhar em salas de aula para educação a crianças questões como:

- Estratificação social e racial. 
- Oportunização à criança da aprendizagem e do reconhecimento de seus próprios preconceitos a fim de combatê-los.

- O diálogo em sala de aula sobre privilégios da cor da pele e a prática do racismo em suas comunidades.

- O auxílio a alunos, ainda na infância, para encontrarem caminhos para criar identidades raciais positivas.

A presença de discussões sobre raça, racismo e brancura torna-se necessária porque a maioria da população brasileira sofre ou já sofreu alguma espécie de preconceito, e, por falhas em sua formação, o cidadão(ã) brasileiro(a) torna-se um indivíduo extremamente preconceituoso, discriminando e afastando as pessoas que não satisfazem as suas expectativas.

Dada a organização social e racial da sociedade brasileira, há somente algumas pessoas que veem, ou seja, só algumas pessoas desenvolvem a empatia necessária para colocar-se no lugar dos outros e sentir na pele o problema da cor.

A brancura da pele muitas vezes funciona como um passaporte a escolhas e privilégios, como algo que coloca algumas pessoas em vantagem e outras em desvantagem. MacIntosh (1999, p. 79) descreve o privilégio branco como:

[...] o pacote invisível de vantagens imerecidas com o qual eu posso contar para retiradas imediatas todos os dias, mas com o qual eu fui "premiado" para manter-me inconsciente. O privilégio branco é como uma invisível maletinha de acessórios especiais, mapas, passaportes, decodificadores de códigos, vistos, roupas, ferramentas e cheques em branco. ${ }^{4}$ [Minha tradução].

Essa problemática que acompanha a brancura da pele na aplicação das políticas de ação afirmativa carrega em si, também, o poder que as instituições têm em recompensar e em penalizar. Elas recompensam oferecendo oportunidades de carreira para alguns e penalizam fechando portas a outros. Sobre as instituições, Enid Lee (1985, p. 12) comenta:

Elas também premiam quando bens com propósitos sociais são distribuídos - decidindo quem recebe treinamento e habilidades, cuidados médicos, educação formal, influência política, apoio moral e respeito próprio, e a promessa de uma segurança futura para a pessoa e para seus filhos. ${ }^{5}$ [Minha tradução].

Para trazer à tona discussões justas sobre as ações afirmativas brasileiras, devemos pensar numa educação racial que englobe o pensar em outros tipos de discriminações. Discriminações que envolvem a etnia, a cultura e a religião.

Pensar e comentar sobre a distribuição desigual dos bens sociais em sala de educação infantil (ou em qualquer outra) é uma tarefa muito complexa. Essa discussão inclui uma formação do professor com discussões sobre os diversos tipos de preconceitos. Professores que assumam seus próprios preconceitos, sua cor, conheçam os privilégios

\footnotetext{
4 "Invisible package of unearned assets which I can count on cashing in each day, but about which I was 'meant' to remain obvious. White privilege is like an invisible weight less knapsack of special provisions, maps, passports, codebooks, tools and blank checks."

5 "They also reward by the way social goods are distributed - by deciding who receives training and skills, medical care, formal education, political influence, moral support and self-respect, productive employment, fair treatment by the law, decent housing, self-confidence, and the promise of a secure future for self and children."
} 
que os cercam (brancura da pele, família, religião etc.) e as barreiras que as pessoas não brancas, não ricas ou não favorecidas encontram. Só com essa formação, com o professor assumindo que há privilégios de acordo com a cor da pele, com a condição social e outros, esse educador poderá encontrar caminhos para criar identidades positivas que façam acontecer as ações afirmativas. Esse seria o caminho para a conscientização de toda a sociedade.

\section{A importância do professor no processo}

Neste estudo, observo que na educação brasileira também está presente a falsa supremacia do colonizador sobre o colonizado. Uma realidade que precisa ser modificada com constante discussão e treinamento que visem à formação de professores para a educação inclusiva.

Preparar professores para combater seus próprios preconceitos em sala de aula requer uma investigação permanente e um querer de cada um desses profissionais em reconhecer seus próprios preconceitos na busca persistente da empatia com o seu aluno.

Essa necessária busca da empatia professor/aluno é essencial em todo processo educacional brasileiro, no entanto, na maioria das vezes não tem sido observada. Por isso é fundamental que a formação do professor contenha, necessariamente, o conhecimento sobre raça, sobre privilégios e por que não incluir o conhecimento sobre antropologia, ou seja, formar o professor brasileiro com estudos sobre as relações entre as pessoas nas escolas, ou, mais especificamente, no interior da sala de aula.

Ao estudar e discutir a implementação das ações afirmativas, não se pode deixar de lembrar o saudoso educador brasileiro Paulo Freire e sua luta ao defender o papel da conscientização, da necessária decifração do mundo por meio da educação em sala de aula. Uma educação que cada profissional deveria professar "ir além das aparências", pagando o preço da crítica, da busca, da transgressão, da desobediência, enfim, como Freire se referia: a educação em busca da libertação. Esse retorno a Paulo Freire leva-me a seguinte interrogação: seria a libertação procurada por Freire o total desaparecimento dos preconceitos em nossas salas de aula?

Observo que um dos caminhos mais seguros para a prática de ações afirmativas é a discussão, com a troca de informações, experiências e situações sobre a vivência de cada um. Discutir situações pode ajudar professores a tomarem consciência de diferentes modos e experiências individuais e institucionais de preconceitos que diferem e ao mesmo tempo são similares. A discussão das diferentes formas de discriminação (o racismo, o antissemitismo, o sexismo etc.) provê professores com um modelo diferente de pensar sobre os preconceitos institucionais.

Segundo McIntosch (1999) e Oslon (1999), são várias as vantagens e os privilégios que são ignorados pelo professor e que precisam ser conhecidos, discutidos e eliminados. Privilégios imerecidos que são garantidos por causa da identidade racial branca. A pedagoga antirracista 
Peggy McIntosh (1999, p. 9) lista 26 dos privilégios que são atados à identidade racial branca, em seu "clássico" artigo sobre os privilégios da cor, que incluem:

1) Poder alugar ou comprar uma moradia em área que se dispõe dos recursos para tal e na qual gostaria de viver;

2) Poder ligar a televisão ou ir à primeira página do jornal e ver pessoas de sua cor extensamente representadas;

3) Poder calçar ou vestir artefatos de segunda mão, ou não responder cartas, por exemplo, sem ter pessoas atribuindo essas escolhas à má moralidade ou a pobreza;

4) Poder solicitar "uma pessoa para carregar", sem achar que irá se defrontar com uma pessoa de sua própria raça; e

5) Estar certo de que se precisar de ajuda legal ou médica, sua raça não trabalhará contra ela. ${ }^{6}$ [Minha tradução].

Uma das mais importantes implicações dessa numeração é que leva professores brancos a reconhecerem que racismo não é só algo que põe outras pessoas em desvantagem, mas que coloca nossos alunos brancos e nós mesmos em vantagem, como já explicitamos acima.

Acredito que o aprender sobre o privilégio branco conduz professores a uma maior responsabilidade. Ir além da leitura sobre privilégios brancos, ir à descrição deles por nós mesmos, talvez seja a mais poderosa arma contra os preconceitos. Lee, Menkart e Okazawa-Rey (1999) sugere que durante uma semana os professores mantenham um diário de privilégios brancos, descrevendo os modos como esses privilégios ocorrem em sua própria escola e comunidade e, então, os compartilhem com seus colegas. Rita Tenório (apud Goldstein, p. 9), em seu ensaio, escreve uma pequena lista das várias maneiras como as crianças brancas podem ser privilegiadas no dia a dia das escolas infantis:

a) As crianças brancas não são informadas por seus colegas: "Você não pode ser a rainha; não existe nenhuma rainha preta".

b) As crianças brancas não são informadas que eles não existem porque todos os índios foram mortos por vaqueiros.

c) As crianças brancas, que falam inglês como uma primeira língua, não têm que se preocupar com aqueles seus colegas que não querem se sentar próximo a eles porque eles "falam engraçado".

d) As crianças brancas não são informadas que elas são "muito brancas" e que seus colegas estão felizes por serem mais escuros que eles porque ser mais escuro é melhor. ${ }^{7}$ [Minha tradução].

Após leitura e reflexão das experiências, acredito que a formação de professores no Brasil demanda não só a discussão de experiências diversas de educação e instrução, mas também de vários treinamentos, ensinando professores a se verem como realmente são, conscientizando-os, desse modo, de suas injustas vantagens.
6 " "(1) being able to rent or purchase housing in an area which she can afford and in which she would want to live; (2) being able to turn on the television or go to the front page of the newspaper and see people of her race widely represented; (3) being able to swear, or dress in second hand clothes, or not answer letters, without having people attribute these choices to the bad morals, the poverty or the illiteracy of her race; (4) being able to ask for 'the person in charge' and find herself facing a person of her own race; and (5) being sure that if she needs legal or medical help, her race will not work against her."

7 "White children are not told by their classmates, 'You can't be the queen; there are no black queens'. White children are not told that they do not exist because cowboys killed all the Indians. White children who speak English as a first language do not have to worry that one of their classmates will not want to sit next to them because they 'talk funny'. White children are not told that they are 'too white' and that their classmates are glad they are darker than them because being darker is better." 
Como exemplo de conscientização pela discussão, recorro ao texto de Tara Goldstein (2001, p. 9), quando a autora relata sobre os momentos mais marcantes do seu curso de educação para a equidade e apresenta o seguinte relato de um de seus alunos:

\begin{abstract}
Nosso trabalho em torno do privilégio branco e do racismo institucional foi a parte mais importante do curso para mim, porque ele me fez questionar sobre minha vida de novas maneiras... Existem várias frases e ideias no artigo (McIntosh) que ressoaram em mim. Primeiro, a parte onde diz que "a brancura me protege" de muitas das angústias que as pessoas de cor enfrentam todo dia. Para mim, isso significa que as coisas que eu tenho conseguido estão todas estigmatizadas, porque elas não foram ganhas graças aos meus méritos ou minhas habilidades, mas, em grande parte, por causa da cor de minha pele. Isso foi de difícil compreensão para mim, porque eu sempre me orgulhei das coisas que eu alcancei e sempre me considerei uma pessoa de muita sorte por ter podido alcançá-los. Agora eu sei que esta é a essência do privilégio branco. Ser branco é ser um dos sortudos. ${ }^{8}$ [Minha tradução].
\end{abstract}

Embora reconhecendo que conscientizar sobre o privilégio, qualquer que seja ele, possa ser doloroso, porque isso significa desistir do mito da meritocracia, acredito que essa compreensão seja um componente chave da educação empática. Uma educação que leve à libertação e à verdadeira inclusão social e cultural, com a prática das políticas de ações afirmativas desnudas de olhares preconceituosos e discriminantes.

\section{Algumas considerações}

Como vimos acima, desde que se iniciaram as aplicações das primeiras ações de políticas afirmativas, a sociedade brasileira tem demonstrado variados pontos de vista sobre o tema. Na maioria das vezes, esses pontos de vista são expressos sem um mínimo de conhecimento sobre o tema e os propósitos aos quais se referem.

Não foi minha pretensão fazer um estudo jurídico sobre ações afir-

8 "Our work around white privilege and institutional racism was the hardest part of the course for me because it made me question my life in new ways ... There were several phrases and ideas in [McIntosh's] article that resonated with me. First, the part where McIntosh says that 'whiteness protected me' from many of the distresses that people of colour face every day. For me, this meant that the things I had achieved were all scarred because they were not wholly earned on merit or ability, but rather in part because of the colour of my skin. This was a difficult realization for me because I have always been proud of the things I have achieved and consider myself lucky for having been able to achieve them. I now know that this is the essence of white privilege. To be white was to be one of the lucky ones." mativas, mas é necessário que a sociedade brasileira, antes de se colocar a favor ou contra essas políticas, compreenda o sentido de princípio na sua acepção jurídica.

A sociedade em geral sabe que o tratamento discriminatório é o diferenciado e que a discriminação negativa é a calcada no desrespeito à igualdade, ao passo que pouco se sabe e pouco se discute sobre a discriminação positiva, fundada em manter ou tornar viável a igualdade.

O princípio constitucional da igualdade tem dois sentidos: o formal, que se consubstancia no tratamento jurídico propriamente dito, explicitado na igualdade de todos perante a lei, impondo ao Estado o dever de agir igualitariamente com os administrados; e o sentido material, que implica em oportunidade, acesso aos meios de produção por intermédio de políticas públicas, ações reais de inserção de todos na sociedade, o que induz à justiça social. 
No sentido formal da igualdade, a sociedade brasileira é igual em sua totalidade, porém, no sentido material, ainda temos um longo caminho a trilhar. Quando sugiro uma educação que clareie o tema de raça, racismo e privilégios da cor da pele, desde o ensino para crianças, estou pensando que é esse o grande desafio para se praticar no presente e no futuro as ações afirmativas: uma educação que traga ao cenário brasileiro a retirada do papel da igualdade material e coloque-a em prática.

Ao adotar ações afirmativas, inicia-se uma tarefa árdua, porque é essencial ao direito de igualdade. Isso porque o princípio da igualdade não é de cunho superior aos demais princípios constitucionais. O jurista Dworkin (1999, p. 492) reconhece a necessidade de apoio da sociedade para que as desigualdades sejam eliminadas e diz isso de forma incidente quando afirma que:

[...] é uma atitude contestadora que torna todo cidadão responsável por imaginar quais são os compromissos públicos de sua sociedade com os princípios, e o que tais compromissos exigem a cada nova circunstância.

No entanto, com as características culturais brasileiras e todos seus vieses, se instauram outras polêmicas. Uma delas estrutura-se em torno da oposição entre políticas de ação afirmativa e políticas universalistas sociais mais amplas. No âmbito do acesso ao ensino superior, esse debate contrapõe o uso do sistema de cotas a um maior investimento na educação básica e na expansão da educação superior.

O problema maior é cultural e reside na crença de que todos têm oportunidades iguais. Há aqueles que defendem políticas universalistas e que argumentam que é necessário olhar a raiz do problema, no caso, a baixa qualidade do ensino básico na esfera pública e as poucas vagas oferecidas pelas instituições de ensino superior. Outros apoiam políticas de ações afirmativas e afirmam que não deveria haver uma oposição entre as políticas adotadas, mas sim uma combinação entre elas.

De acordo com Guimarães (1999), ações afirmativas não dispensam, mas exigem uma política mais ampla de igualdade de oportunidades implementada conjuntamente, já que as ações afirmativas são políticas restritas e limitadas, uma exceção utilizada apenas naqueles locais em que o acesso de um grupo é comprovadamente inadequado. Dessa forma, enquanto os ensinos fundamentais e médios exigem uma universalização, o ensino superior necessitaria de medidas que garantissem o ingresso de certos grupos dele sistematicamente excluídos não por mérito ou dotes intelectuais, mas por critérios raciais e sociais.

Uma segunda questão, ainda relacionada a essa polêmica, é o debate entre o uso de políticas redistributivas (de caráter social) ou de políticas contrárias à discriminação (de caráter racial), ou uma combinação de ambas. No Brasil, ainda é forte a ideia de que uma política direcionada à população pobre necessariamente beneficiaria os negros, por exemplo, já que estariam em maioria nessa camada. Aqueles que discordam dessa posição argumentam que ela esquece a especificidade do problema racial, 
já que a exclusão social não seria a mesma coisa que a discriminação racial.

No entanto, o que deve sobrepor-se a todas essas questões é que a ação afirmativa evidencia a democracia e o princípio da igualdade com respeito às diferenças. É uma maneira de passarmos a reconhecer todas as pessoas no Brasil como cidadãos, ou seja, dar voz à diferença, à multiculturalidade. Sobre a importância de se dar voz à pessoa humana, Bell Hooks (apud Giroux, 1999, p. 198) comenta:

[...] dar voz significa passar do silêncio para a fala com a atitude revolucionária [...] a ideia de encontrar a própria voz ou ter a própria voz assume uma primazia no discurso falado, na escrita e na ação [...] Somente como sujeitos nós podemos falar. [...] como objetos, permanecemos sem voz - nossos seres são definidos e interpretados por outros $[\ldots]$.

\section{Considerações finais}

A discussão sobre políticas afirmativas e todas as atividades que as englobam é extensa e não conclusa. No entanto, acredito que a construção do sujeito na escola, com trabalho responsável de conscientização, é o melhor caminho para sua prática.

Ademais, creio que com educação de crianças para o exercício da cidadania, com conhecimento sobre raça, racismo e privilégios, há de se fazer no Brasil o que McLaren (1999, p. 134) chama de uma reescrita das diferenças, ou seja, "tentativas de mudança dramática das condições materiais que permitem que as relações de dominação prevaleçam sobre as relações de igualdade e justiça social".

Necessário será formar professores dispostos à prática pedagógica e que conduzam seus alunos a reconhecer e respeitar as diferenças para que as ações positivas sejam debatidas com conhecimento de causa e passem a fazer parte da prática do cidadão brasileiro.

Desde a implantação de cotas para as universidades brasileiras, alunos que antes não tinham acesso ao estudo superior têm ingressado e galgado um lugar de ascensão social, trazendo desse modo, para a discussão das ações afirmativas, a negação da assertiva presente em discursos racistas e preconceituosos de que as pessoas conseguem ou não galgar a escala social por seus próprios méritos; pensamento defendido (e crível) de que a estrutura de oportunidades de trabalho seja a mesma para todos os brasileiros.

No Brasil, pessoas de origem européia ou de pele branca se permitem ignorar a importância da cor da pele na perpetuação da discriminação racial, fenômeno também observado na "cegueira" das pessoas que se deslocam dos grandes centros para as regiões do interior do País; pessoas que conduzem em si as características da supremacia do colonizador e demonstram o pior sentido da palavra "colo": o que discrimina, subjuga e intimida.

Com a educação da criança quanto à empatia e ao respeito às diferenças, construiremos um caminho para a mudança dessa visão de 
oportunidades iguais, pois somente com a compreensão de que oportunidades iguais, frequentemente válidas para brancos e não necessariamente válidas para pessoas de cor, é que essa geração será conduzida a reconhecer a importância da visão de diferentes raças ao se discutir o acesso às oportunidades e a consequente valorização de se colocar em prática as várias ações afirmativas.

\section{Referências bibliográficas}

BERNARDINO, Joaze. Levando a raça a sério: ação afirmativa e correto reconhecimento. In: BERNARDINO, Joaze; GALDINO, Daniela (Orgs.). Levando a raça a sério: ação afirmativa e universidade. Rio de Janeiro: DP\&A, 2004.

BRASIL. Senado. Comissão de Constituição, Justiça e Cidadania do Senado. Projeto de lei $n^{\circ}$ 13: relatório. Relator Lúcio Alcântara. 25 jun. 1997.

DELGADO, Richard; STEFANCIC, Jean. Introduction. In: DELGADO, R.; STEFANCIC, J. (Org.). Critical race theory: the cutting edge. Philadelphia: Temple University Press, 1997.

DWORKIN, Ronald. O império do Direito. São Paulo: Martins Fontes, 1999.

ECO, Umberto. Trattato di semiótica generale. Milan: Bompiani, 1975. [English version: A Theory of Semiotics. Bloomington: Indiana UP, 1976].

GIROUX, H. A. Cruzando as fronteiras do discurso educacional: novas políticas em educação. Porto Alegre: Artemed. 1999.

GOLDSTEIN, Tara. 'I'm Not White': anti-racist teacher education for white early childhood educators. Contemporary Issues in Early Childhood, v. 2, n. 1, p. 3-13, 2001. Disponível em: < http://www. wwwords.co.uk/rss/abstract.asp?j= ciec\&aid $=1534>$.

GOMES, Joaquim Benedito Barbosa. Ação afirmativa e princípio constitucional da igualdade: o direito como instrumento de transformação social - a experiência dos EUA. Rio de Janeiro: Renovar, 2001.

GUIMARÃES, Antonio Sérgio Alfredo. Racismo e antirracismo no Brasil. São Paulo: Editora 34, 1999. 
LEE, E. Displacement and discrimination: a double burden for workers of colour. TESL Talk, v. 21, p. 102-117, 1993.

. Letters to Marcia: a guide to antiracist education. Toronto: Cross-Cultural Communication Centre. 1985.

LEE, E.; MENKART, D.; OKAZAWA-REY, M. (Eds.). Beyond heroes and holidays: a practical guide to K-12 anti-racist, multicultural education and staff development. Washington, DC: Network of Educators on the Americas, 1999. [Available from NECA, PO Box 73038, Washington DC, USA 20056-3038; e-mail: necadc@aol.com].

MCLAREN, P. Multiculturalismo crítico. São Paulo: Cortez, 1999.

MCINTOSH, P. White privilege: unpacking the invisible knapsack. In: LEE, E.; MENKART, D.; OKAZAWA-REY, M. (Eds.). Beyond heroes and holidays: a practical guide to K-12 anti-racist, multicultural education and staff development. Washington, DC: Network of Educators on the Americas, 1999 [1988]. p. 79-82.

MUNANGA, Kabengele. Políticas de ação afirmativa em benefício da população negra no Brasil: um ponto de vista em defesa de cotas. In: SILVA, Petronilha B. G. e; SILVÉRIO, Valter R. (Orgs.). Educação e ações afirmativas: entre a injustiça simbólica e a injustiça econômica. Brasília, 2003. Disponível em: < http://www.dominiopublico.gov.br/ pesquisa/DetalheObraForm.do?select_action $=\&$ co_obra $=5216>$.

. Rediscutindo a mestiçagem no Brasil: identidade nacional versus identidade negra. Petrópolis: RJ: Vozes, 1999.

. O anti-racismo no Brasil. In: MUNANGA, Kabengele (Org.). Estratégias e políticas de combate à discriminação racial. São Paulo: Edusp, 1996. p. 79-111.

OLSON, R. A. White privilege in schools. In: LEE, E.; MENKART, D.; OKAZAWA-REY, M. (Ed.). Beyond heroes and holidays: a practical guide to K-12 antiracist, multicultural education and staff development. Washington, D.C.: Network of Educators on the Americas, 1999. p. 83-84.

SLEETER, C. Teaching whites about racism. In: LEE, E.; MENKART, D.; OKAZAWA-REY, M. (Eds.). Beyond heroes and holidays: a practical guide to K-12 antiracist, multicultural education and staff development. Washington, DC: Network of Educators on the Americas, [1996] 1999. p. 36-44. 
Klondy Lúcia de Oliveira Agra, mestre em Linguística pela Universidade Federal de Rondônia, é professora titular de Língua Inglesa e Comunicação Empresarial da Faculdade Interamericana de Porto Velho (Uniron).

klondy2@gmail.com

Recebido em 19 de abril de 2011.

Aprovado em 18 de abril de 2012. 